\title{
Correction to: Retrofitting towards energy-efficient homes in European cold climates: a review
}

\author{
Laurina C. Felius • Fredrik Dessen • \\ Bozena Dorota Hrynyszyn
}

Published online: 7 January 2020

(C) Springer Nature B.V. 2020

Correction to: Energy Efficiency

https://doi.org/10.1007/s12053-019-09834-7

The original version of this paper was unfortunately published with an error in Fig. 3. The published figure includes excess layers, which negatively affect the readability of the figure. The correct figure is displayed below. The authors apologize for this error.

The online version of the original article can be found at https://doi.org/10.1007/s12053-019-09834-7

L. C. Felius • B. D. Hrynyszyn ( $₫)$

Department of Civil and Environmental Engineering, Faculty of Engineering, NTNU - Norwegian University of Science and

Technology, Trondheim, Norway

e-mail: bozena.d.hrynyszyn@ntnu.no

F. Dessen

Department of Engineering Cybernetics, Faculty of Information Technology and Electrical Engineering, NTNU - Norwegian University of Science and Technology, Trondheim, Norway 


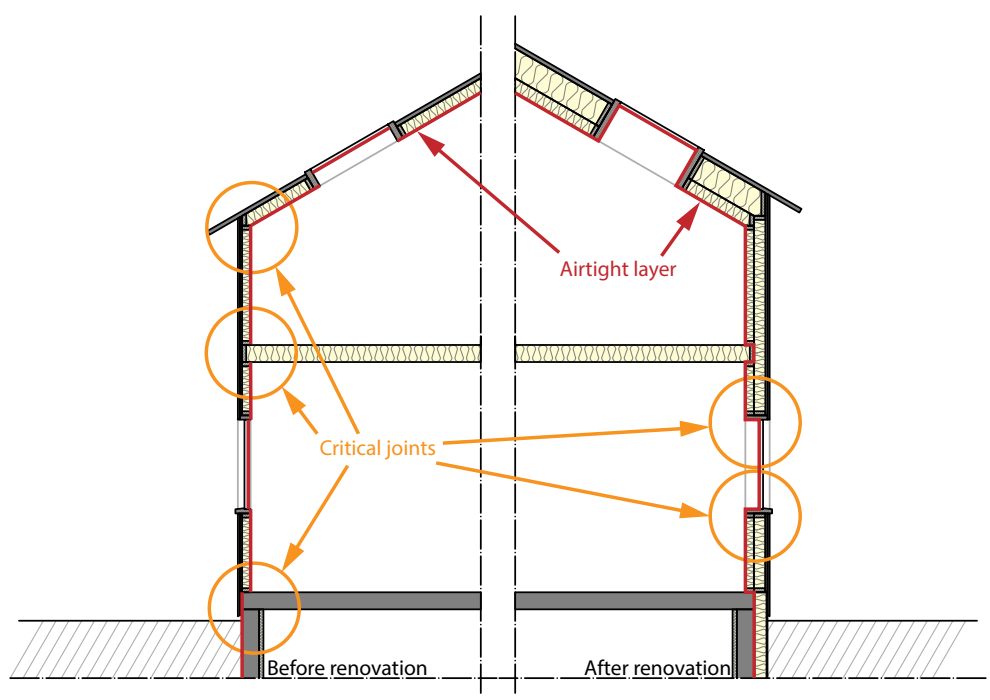

Fig. 3 Typical critical joints for thermal bridges in a residential building. This illustration shows the noncontinuous airtight layer of an existing house on the left and a retrofitting solution with added external insulation, a continued airtight layer and windows placed in the new insulation layer on the right

Publisher's note Springer Nature remains neutral with regard to jurisdictional claims in published maps and institutional affiliations. 